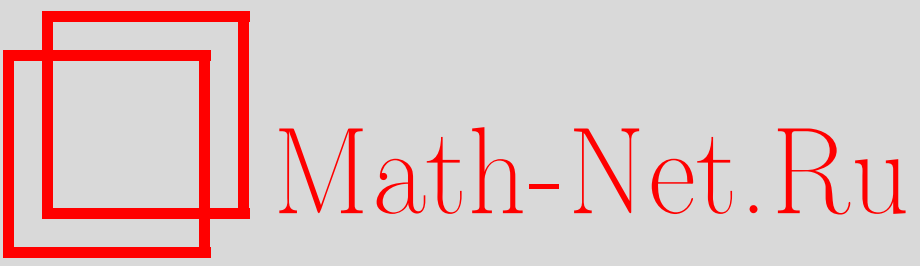

М. И. Штогрин, Специальные изометрические преобразования поверхностей платоновых тел, УМН, 2005, том 60, выпуск 4, 221-222

DOI: https://doi.org/10.4213/rm1453

Использование Общероссийского математического портала Math-Net.Ru подразумевает, что вы прочитали и согласны с пользовательским соглашением

http://www.mathnet.ru/rus/agreement

Параметры загрузки:

IP: 54.237 .206 .68

26 апреля 2023 г., 16:03:21 


\title{
СПЕЦИАЛЬНЫЕ ИЗОМЕТРИЧЕСКИЕ ПРЕОБРАЗОВАНИЯ ПОВЕРХНОСТЕЙ ПЛАТОНОВЫХ ТЕЛ
}

\author{
М. И. Штогрин
}

Специальные изометрические преобразования цилиндрической поверхности открыл и исследовал А. В. Погорелов $[1 ; \S 3$, п. 1]. Они обладают определенной правильностью строения. Для их описания рассматривается вспомогательная правильная призма с четным числом сторон. Обозначим ее через П. Она обладает вертикальной осью. На ее боковых гранях строятся конгруэнтные гладкие кривые $\gamma_{1}, \ldots, \gamma_{2 n}$, см. [1; рис. 12], на которые натягиваются цилиндрические поверхности $Z_{12}, Z_{23}, \ldots, Z_{2 n-12 n}, Z_{2 n} 1$ с горизонтальными образующими, см. [1; рис. 13$]$. Все вместе они составляют поверхность $Z$, изометричную иилиндрической поверхности. Пусть каждая кривая $\gamma_{i}$ в любой своей точке имеет нулевую кривизну, т.е. каждая ребристая линия $\gamma_{i}$ реально представляет собою прямолинейное ребро $\ell_{i}, i=1, \ldots, 2 n$. Тогда мы получим следующие три естественных частных случая:

(1) если отрезок $\ell_{i}$ разбивает грань призмы П на два равных прямоугольника, то поверхность $Z$ представляет собою правильную призму, обозначим ее через $P$, см. рис. 1 ;

$(2)$ если отрезок $\ell_{i}$ разбивает грань призмы П на две равных трапеции, то поверхность $Z$ состоит из конгруэнтных равнобочных трапеций, обозначим ее через $T$, см. рис. 2 ;

(3) если отрезок $\ell_{i}$ разбивает грань призмы П на два равных треуголшника, то поверхность $Z$ представляет собою антипризму, обозначим ее через $A$, см. рис. 3 .

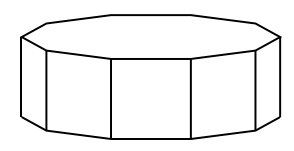

Рис. 1. $Р$

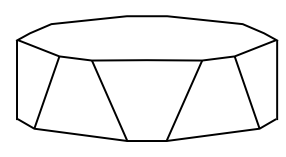

Рис. 2. Т

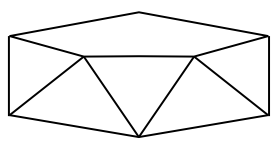

Рис. 3. A

В случае (2) отрезок $\ell_{i}$ может пробегать все промежуточные положения (вакансии) между двумя крайними положениями (1) и (3). Однако, среди бесконечного числа этих вакансий для отрезка $\ell_{i}$ впредь мш выберем и зафиксируем только одну из них.

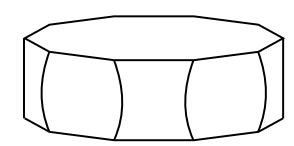

Рис. 4. $Z(P)$

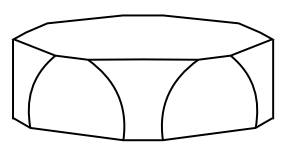

Рис. 5. $Z(T)$

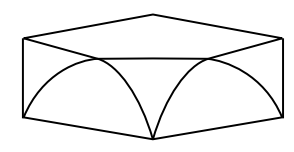

Рис. 6. $Z(A)$

ЗАмЕчАниЕ 1 . Изометричная цилиндру кусочно линейная поверхность $Z$ как пояс натянута на прямолинейные боковые ребра $\ell_{i}$ с плавающими вдоль краев призмы П концами. При изменении положений отрезков $\ell_{i}$ на гранях призмы П вложение цилиндрической поверхности в $\mathbb{R}^{3}$ остается изометрическим [1]. При вращениях отрезков $\ell_{i}$ вокруг центров граней мы получаем однопараметрическое изгибание поверхности $T$ в $\mathbb{R}^{3}$. Двум крайним значениям параметра соответствуют изометричные поверхности $P$ и $A$.

Теперь, следуя [1], в каждом конкретном случае $(1),(2)$ или (3) построим гладкие кривые $\gamma_{i}$ вновь, причем так, чтобы на этот раз они обладали общими концами с уже выбранными на гранях призмы П отрезками $\ell_{i}$ (см. рис. $1,2,3$ и рис. $4,5,6$ соответственно). Если опять во всех точках кривой $\gamma_{i}$ мы будем непрерьвно уменьшать кривизну, устремляя ее к нулю, то деформируемая ребристая линия $\gamma_{i}$ в пределе выпрямится в прямолинейное ребро $\ell_{i}$. А так как при изменении кривой $\gamma_{i}$ вложение цилиндрической поверхности в $\mathbb{R}^{3}$ остается изометрическим [1], то

Работа выполнена при финансовой поддержке Российского фонда фундаментальных исследований (грант № 05-01-00170), Совета по грантам Президента РФ для поддержки ведущих научных школ (грант НШ-2185.2003.1) и программы ОМН РАН "Современные проблемы теоретической математики". 
мы получим пример непрерьвного изгибания поверхности $Z$ в $\mathbb{R}^{3}$. В резултате данного изгибания кусочно гладкая поверхность $Z$ превратится в кусочно линейную поверхность $P$ в случае (1), $T$ в случае (2) или $A$ в случае (3).

ЗАмЕчАНиЕ 2. В процессе непрерывного изгибания концы переменных криволинейных ребер $\gamma_{i}$ закреплены на поверхности $Z$ и к краям поверхности $Z$ можно приклеить два основания, превратив ее в замкнутую поверхность неотрицательной кривизны. В первых двух случаях замкнутая поверхность имеет 2 плоские $2 n$-угольные грани, $2 n$ кривых 4 -угольных граней, $4 n$ прямолинейных ребер, $2 n$ криволинейных ребер, $4 n$ вершин. В третьем случае замкнутая поверхность имеет 2 плоские $n$-угольные грани, $2 n$ кривых 3 -угольных граней, $2 n$ прямолинейных ребер, $2 n$ криволинейных ребер, $2 n$ вершин. Во всех трех случаях криволинейные ребра $\gamma_{i}$ (не геодезические на $Z$ ) возникли не вдруг, а взамен прямолинейных ребер $\ell_{i}$ (геодезических на $Z$ ). Особенность процесса изгибания состоит в том, что ребристая линия $\gamma_{i}$ на гребне волны плавно перекатьвается вдоль пояса $Z$. (См. непрерывное изгибание в случае зеркального выпучивания вьпуклой поверхности $[1 ;$ с. 45$]$.)

Применим сказанное к поверхностям платоновых тел. А именно, пусть плоское сечение поверхности, перпендикулярное оси симметрии платонова тела, не содержит вершин тела и при этом является замкнутой геодезической линией на поверхности. Тогда все рассматриваемые параллельные сечения составляют поя $c$, вырезаемый из поверхности двумя крайними параллельными плоскостями, проходящими через вершины тела. Как оказалось, пояс имеет вид одной из поверхностей $P, T$ или $A$. В самом деле, на поверхности куба пояс с осью 4 -го порядка - это призма $P$. На поверхности додекаэдра пояс с осью 3 -го порядка - это поверхность $T$. На поверхности тетраэдра, октаэдра, куба, додекаэдра, икосаэдра пояс с осью 2-, 3-, 3-, 5-, 5-го порядка соответственно - это антипризма $A$.

Далее, кусочно линейный пояс $P, T$ или $A$, принадлежащий поверхности платонова тела, заменим на изометричньй кусочно гладкий пояс $Z=Z(P), Z=Z(T)$ или $Z=Z(A)$, см. pис. 4-6. На всех трех рисунках крайняя левая (правая) ребристая линия $\gamma_{i}$ проектируется в прямолинейный отрезок. Получим кусочно гладкое вложение поверхности платонова тела в $\mathbb{R}^{3}$. Во всех случаях пояс $Z$ имеет кривые боковые ребра $\gamma_{i}$. В трех случаях на поверхности возникают новые прямолинейные ребра: их 10 в случае пояса с осью 5-го порядка для додекаэдра, их по 6 в случае пояса с осью 3-го порядка для додекаэдра и куба.

И, наконец, если во всех точках гладких кривых $\gamma_{i}$ пояса $Z$ устремить кривизну ребристой линии $\gamma_{i}$ к нулю, то кривые ребра $\gamma_{i}$ (они не геодезические на поверхности $Z$; они произвольно ${ }^{1}$ выбираются в плоскостях боковых граней призмы П, см. [1]) с закрепленными концами (концы переменных ребер $\gamma_{i}$ закреплены на изгибаемом поясе $Z$, а не в объемлющем пространстве $\mathbb{R}^{3}$ ) продеформируются в прямолинейные ребра $\ell_{i}$ (геодезические на поверхности $Z$ ). Получим непрерывное кусочно гладкое изгибание поверхности платонова тела с плавно меняющимся в $\mathbb{R}^{3}$ поясом $Z$ с переменными кривыми ребрами $\gamma_{i}$.

Теорема. Поверхности платоновых тел допускают кусочно гладкие изгибания.

Случай оси 2-го порядка для тетраэдра является особьм, так как пояс представляет собою особую антипризму $A$ : ее основания вырождены - это два противоположных ребра тетраэдра. Однако данньй пояс $A$ можно заменить на кусочно гладкий пояс $Z(A)$. Значит, тетраэдр допускает непрерьвное изгибание, при котором два противоположных ребра остаются прямолинейными, а четыре остальных ребра деформируются в криволинейные. Получены сугубо кусочно гладкие вложения поверхности тетраэдра в трехмерное евклидово пространство $\mathbb{R}^{3}$. Они без линейных участков: все четыре треуголшные грани нелинейные. Этим они отличаются от других вложений, представленных выше и в [2].

\section{СПИСОК ЛИТЕРАТУРЫ}

[1] А. В. Погорелов. Изгибания поверхностей и устойчивость оболочек. Киев: Наукова думка, 1998. [2] М.И. Штогрин // УМН. 2004. Т. 59. № 5. С. 167-168.

Математический институт им. В. А. Стеклова РАН

E-mail: stogrin@mi.ras.ru Представлено В.М. Бухштабером
Принято редколлегией 23.05.2005

\footnotetext{
${ }^{1}$ Речь идет о произволе в выборе образа в $\mathbb{R}^{3}$, а не прообраза на абстрактном цилиндре.
} 